\title{
Current Treatment Strategies in Cutaneous Malignant Melanoma of the Head and Neck
}

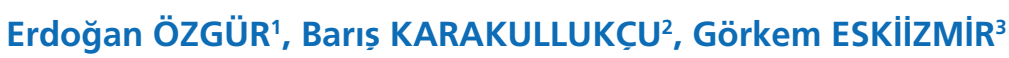 \\ 1 Muğla Sitkı Koçman University, Department of Otorhinolaryngology, Muğla, Turkey - ORCID ID:0000-0003-2494-4244 \\ 2 The Netherlands Cancer Institute, Antoni van Leeuwenhoek Hospital, Department of Head and Neck Oncology and Surgery, Amsterdam, \\ THE NETHERLANDS - ORCID ID:0000-0002-1700-5743 \\ 3 Manisa Celal Bayar University, Department of Otorhinolaryngology, Manisa, TURKEY - ORCID ID:0000-0002-3125-8288
}

\begin{abstract}
Cutaneous malignant melanoma is potentially an important health problem for white people. The incidence of melanoma is rising faster than other solid cancers. Despite the new melanoma drugs surgery for localised melanoma and regional metastasis is still the standard of care. However management of cutaneous melanoma differs from other cancers at some points such as biopsy tech-
\end{abstract}

nique, surgical margine, incorporation ofsentinel lymph node biopsy for staging etc. In this review we focused on the role of the head and neck surgeon in management of cutaneous melanoma of head and neck region according to current knowledge.

Keywords: Melanoma, head and neck neoplasms, surgery, sentinel lymph node biopsy

\section{Introduction}

Malignant melanoma of the head and neck is relatively rare among skin cancers. However, it is an important health problem because of its morbidity and mortality. Cutaneous melanoma is responsible for up to $75 \%$ of skin cancer deaths ${ }^{[1]}$. According to the data of the World Health Organization, the incidence of cutaneous melanoma is on the rise particularly in developed and developing countries where fair-skinned people exposed to the sun ${ }^{[2]}$. The incidence rate is $<10-25$ new melanoma cases per 100.000 inhabitants in Europe; it is 20-30/100.000 inhabitants in the United States of America. Of note, the highest incidence is in Australia, which is 50-60/100.000 inhabitants ${ }^{[3]}$. According to the GLOBOCAN 2012 report, the estimated number of new cases expected in developed countries is about 100.000 in men and women ${ }^{[4]}$.
In Turkey, approximately 2.600 new cases are detected every year ${ }^{[5]}$. Even though ultraviolet exposure is the major etiologic factor for melanoma and non-melanoma skin cancers; melanoma differs from non-melanoma skin cancers in several aspects such as tumor biology and behavior, and metastatic cascade. The typical phenotype of a melanoma patient is pale white skin, red or blond hair, and blue eyes. About $80 \%$ of patients with head and neck cutaneous melanoma are older than 80 years ${ }^{[6]}$. For head and neck cutaneous melanoma face, scalp, neck and external ear are the most common regions as have the highest potential for sun exposure. Moreover, the phenotypic characteristics and environmental factors and immunosupression are the major risk factors for malignant melanoma particularly in transplant patients ${ }^{[6]}$. Classically, four subtypes of cutaneous melanomas can be identified histologically and clinically: superficial spread-
Correspondence: Erdoğan Özgür

Muğla Sıtkı Koçman University, Department of Otorhinolaryngology, 48000, Kötekli, Muğla, TURKEY

e-mail: erduvan@hotmail.com

Received: October 27, 2018; Accepted: February 6, 2019
Online available at: www.entupdates.org

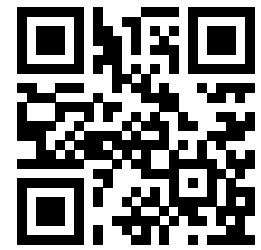


ing melanoma, nodular melanoma, lentigo maligna melanoma, acral lentiginous melanoma. Superficial spreading melanoma is the most frequent histopathologic subtype, composing about $59 \%$, followed by nodular melanoma at $21 \%$, and lentigo-maligna melanoma at $11 \%{ }^{[7]}$.

Moreover cutaneous malignant melanoma differs with TNM staging than the other skin cancers (Table 1) ${ }^{[8]}$. Correct staging constitutes the first step of melanoma management. The diagnosis and treatment of malignant melanoma of the head and neck require a multidisciplinary teamwork including head and neck surgeon, dermatologist, radiation oncologist, medical oncologist, radiologist and pathologist. The purpose of the current review was to comprehensively discuss the role of head neck surgeons in perspective of three subtitles: (i) the biopsy technique in malignant melanoma, (ii) surgical excision of primary tumor in malignant melanoma, and (iii) the management of lymph nodes in malignant melanoma.

\section{(i) Biopsy Technique in Cutaneous Malignant Melanoma}

\section{Which biopsy technique should be performed for malignant melanoma?}

Early diagnosis of melanoma is a cornerstone for treatment success. Melanoma develops from precursor lesions in approximately $20-40 \%$ of cases ${ }^{[9]}$. The changing and evolving features of a nevi are characteristic signs of a melanoma. These features are abbreviated as "ABCDE" signs of melanoma ( $\underline{A}$ symmetry, irregular $\underline{B}$ orders, $\geq 1$ or uneven distribution of $\underline{C}$ olor, large $(\geq 6 \mathrm{~mm}) \underline{D}$ iameter, the $\underline{E}$ volution of a mole) which can be detected using a dermoscope or confocal laser scanning microscopy. Therefore, use of a dermoscopy may provide a remarkable decrease in unnecessary surgeries ${ }^{[10]}$.

The gold standart method for the diagnosis of a clinically suspicion lesion is complete excision with the inclusion of a surgical margin of few millimetres to allow for histopathological examination. However, an incisional or punch biopsies containing all the layers of the dermis may also be performed for suspicious lesions that are adjacent to vital structures (eyes, lips, nose, etc.) and require extensive resection. Incisional biopsies or partial biopsy methods such as curettage or punches should not be performed when an excisional biopsy is technically possible; because it may change histopathological features which are imperative for conclusion and staging. In addition, large tumor resections are not recommended for diagnosis.

\section{What are the key features that should be evaluated in a pathology report of a patient with cutaneous malignant melanoma?}

In cutaneous malignant melanoma, the assessment of a pathology report is of utmost important for accurate staging and treatment plan. Therefore, a close communication with the pathologist is crucial. A pathology report should include:
a. Tumor thickness (Breslow)
b. Level of invasion (Clark)
c. Histopathologic type of melanoma
d. Presence or absence of ulceration
e. Mitotic index
f. Growth phase (horizontal or vertical)
g. Vascular or perineural involvement
h. Lateral and deep surgical margins

Moreover, molecular analysis and mutation tests (BRAF, NRAS or $c$-kit mutations) may be required particularly for patients with distant metastasis or non-resectable regional metastasis, who are candidates of systemic or targeted medical treatment ${ }^{[11]}$. After the histopathological diagnosis of malignant melanoma, a detailed physical examination for other suspicious pigmented lesions, tumor satellites, regional lymph node and systemic metastases should be performed.

\section{What are the required imaging steps after confirming melanoma?}

Routine imaging is not recommended for Stage 0, IA, IB, II melanoma. However, cervical nodal ultrasound imaging should be performed if sentinel lymph node (SLN) biopsy is planned (stage I and II). The next step should be a fine needle or tru-cut biopsy if a suspicious lymph node is detected via ultrasound. Fine-needle aspiration biopsy has been demonstrated to have high sensitivity and specificity for detecting lymph node involvement ${ }^{[12]}$. If a lymph node involvement is detected (stage III), an imaging technique is a prerequisite for the evaluation of distant metastasis. The recommended imaging modalities include contrast enhanced thorax/abdomen/pelvic computerized tomography or whole body positron emission tomography/computerized tomography scan with or without contrast enhanced brain magnetic resonance imaging. It is noteworthy that contrast enhanced neck computerized tomography is generally indicated for cutaneous malignant melanoma of head and neck ${ }^{[13,14]}$. 
Table 1. Melanoma of the Skin Staging (8th Edition).

\begin{tabular}{|c|c|}
\hline \multicolumn{2}{|c|}{ Primary tumor $(\mathrm{T})$} \\
\hline TX & Primary tumor cannot be assessed (ie, curettaged melanoma) \\
\hline T0 & No evidence of primary tumor \\
\hline Tis & Melanoma in situ \\
\hline $\mathrm{T} 1$ & Thickness $\leq 1.0 \mathrm{~mm}$ \\
\hline \multirow{2}{*}{$\begin{array}{l}\text { T1a: } \\
\text { T1b: }\end{array}$} & $<0.8 \mathrm{~mm}$ without ulceration \\
\hline & $<0.8 \mathrm{~mm}$ with ulceration, or $0.8-1.0 \mathrm{~mm}$ with or without ulceration \\
\hline $\mathrm{T} 2$ & Thickness $>1.0-2.0 \mathrm{~mm}$ \\
\hline \multirow{2}{*}{$\begin{array}{l}\text { T2a: } \\
\text { T2b: }\end{array}$} & Without ulceration \\
\hline & With ulceration \\
\hline T3 & Thickness $>2.0-4.0 \mathrm{~mm}$ \\
\hline \multirow{2}{*}{$\begin{array}{l}\text { T3a: } \\
\text { T3b: }\end{array}$} & Without ulceration \\
\hline & With ulceration \\
\hline T4 & Thickness $>4.0 \mathrm{~mm}$ \\
\hline \multirow{2}{*}{$\begin{array}{l}\text { T4a: } \\
\text { T4b: }\end{array}$} & Without ulceration \\
\hline & With ulceration \\
\hline \multicolumn{2}{|c|}{ Regional lymph nodes $(\mathrm{N})$} \\
\hline NX & Regional nodes cannot be assessed (ie, previously removed for another reason) \\
\hline NO & No regional metastases detected \\
\hline N1 & One tumor-involved lymph node or in-transit, satellite, and/or microsatellite meastases with no tumor-involved nodes \\
\hline N1a: & One clinically occult (ie, detected by sentinel lymph node biopsy [SLNB]; no in-transit, satellite, or microsatellite metastases \\
\hline N1b: & One clinically detected; no in-transit, satellite, or microsatellite metastases \\
\hline N1c: & No regional lymph node disease; in-transit, satellite, and/or microsatellite metastases found \\
\hline N2 & Two or three tumor-involved nodes; or in-transit, satellite, or microsatellite metastases \\
\hline \multirow{2}{*}{$\begin{array}{l}\text { N2a: } \\
\text { N2b: }\end{array}$} & Two or three clinically occult (ie, detected by SLNB); no in-transit, satellite, or microsatellite metastases \\
\hline & Two or three clinically detected; no in-transit, satellite, or microsatellite metastases \\
\hline N2c: & One clinically occult or clinically detected; in-transit, satellite, and/or micros atellite metastases found \\
\hline N3 & $\begin{array}{l}\geq 4 \text { tumor-inolved nodes or in-transit, satellite, and/or microsatellite metastases with } \geq 2 \text { tumor-involved nodes or any num- } \\
\text { ber of matted nodes without or with in-transit, satellite, and/or microsatellite metastases }\end{array}$ \\
\hline N3a: & $\geq 4$ clinically occult (ie, detected by SLNB); no in-transit, satellite, or microsatellite metastases \\
\hline N3b: & $\begin{array}{l}\geq 4 \text {, at least one of which was clinicallly detected, or presence of any matted nodes; no in-transit, satellite, or microsatellite } \\
\text { metastases }\end{array}$ \\
\hline N3c: & $\begin{array}{l}\geq 2 \text { clinically occulr or clinically detected and/or presence of any matted nodes, with presence of in-transit, satellite, and/or } \\
\text { microsatellite metastases }\end{array}$ \\
\hline \multicolumn{2}{|c|}{ Distant metastasis (M) } \\
\hline M0 & No detectable evidence of distant metastases \\
\hline M1a & Metastases to skin, soft tissue (including muscle), and/or nonregional lymph nodes \\
\hline M1b & Lung metastasis, with or without M1a involvement \\
\hline M1c & Distant metastasis to non-central nervous system (CNS) visceral sites with or without M1a or M1b involvement \\
\hline M1d & Distant metastasis to CNS, with or without M1a or M1b involvement \\
\hline
\end{tabular}




\section{Clinical Staging}

\begin{tabular}{|c|c|c|c|}
\hline Stage & $\mathrm{T}$ & $\mathrm{N}$ & M \\
\hline 0 & Tis & No & Mo \\
\hline I A & T1a & NO & MO \\
\hline \multirow[t]{2}{*}{ I B } & $\mathrm{T} 1 \mathrm{~b}$ & NO & Mo \\
\hline & $\mathrm{T} 2 \mathrm{a}$ & NO & Mo \\
\hline \multirow[t]{2}{*}{ II A } & $\mathrm{T} 2 \mathrm{~b}$ & NO & Mo \\
\hline & T3a & No & Mo \\
\hline \multirow[t]{2}{*}{ II B } & T3b & No & Mo \\
\hline & $\mathrm{T} 4 \mathrm{a}$ & NO & Mo \\
\hline II C & $\mathrm{T} 4 \mathrm{~b}$ & No & Mo \\
\hline III & Any $T$, Tis & $\mathrm{N} 1, \mathrm{~N} 2$, or N3 & Mo \\
\hline IV & Any $T$ & Any N & M1 \\
\hline \multicolumn{4}{|c|}{ Pathological Staging } \\
\hline Stage & $\mathrm{T}$ & $\mathrm{N}$ & M \\
\hline 0 & Tis & No & Mo \\
\hline I A & $\mathrm{T} 1 \mathrm{a}, \mathrm{T} 1 \mathrm{~b}$ & No & Mo \\
\hline IB & $\mathrm{T} 2 \mathrm{a}$ & No & Mo \\
\hline II A & T2b, T3a & No & Mo \\
\hline II B & T3b, T4a & NO & Mo \\
\hline II C & $\mathrm{T} 4 \mathrm{~b}$ & No & Mo \\
\hline III A & $\mathrm{T} 1 \mathrm{a} / \mathrm{b}, \mathrm{Ta}$ & $\mathrm{N} 1 \mathrm{a}, \mathrm{N} 2 \mathrm{a}$ & Mo \\
\hline \multirow[t]{3}{*}{ III B } & T0 & N1b, N1c & Mo \\
\hline & $\mathrm{T} 1 \mathrm{a} / \mathrm{b}$ & $\mathrm{N} 1 \mathrm{~b} / \mathrm{c}, \mathrm{N} 2 \mathrm{~b}$ & Mo \\
\hline & T2b, T3a & $\mathrm{N} 1 \mathrm{a} / \mathrm{b} / \mathrm{c}, \mathrm{N} 2 \mathrm{a} / \mathrm{b}$ & Mo \\
\hline \multirow[t]{4}{*}{ III C } & T0 & $\mathrm{N} 2 \mathrm{~b} / \mathrm{c}, \mathrm{N} 3 \mathrm{~b} / \mathrm{c}$ & Mo \\
\hline & $\mathrm{T} 1 \mathrm{a} / \mathrm{b}, \mathrm{T} 2 \mathrm{a} / \mathrm{b}, \mathrm{T} 3 \mathrm{a}$ & $\mathrm{N} 2 \mathrm{c}, \mathrm{N} 3 \mathrm{a} / \mathrm{b} / \mathrm{c}$ & Mo \\
\hline & T3b, T4a & Any $\mathrm{N} \geq \mathrm{N} 1$ & Mo \\
\hline & $\mathrm{T} 4 \mathrm{~b}$ & $\mathrm{~N} 1 \mathrm{a} / \mathrm{b} / \mathrm{c}, \mathrm{N} 2 \mathrm{a} / \mathrm{b} / \mathrm{c}$ & MO \\
\hline III D & $\mathrm{T} 4 \mathrm{~b}$ & $\mathrm{~N} 3 \mathrm{a} / \mathrm{b} / \mathrm{c}$ & Mo \\
\hline IV & Any $T$ & Any $\mathrm{N}$ & M1 \\
\hline
\end{tabular}




\section{(ii) Surgical Excision of Primary Tumor in Malig- nant Melanoma}

\section{What is the surgical margin for cutaneous malignant melanoma of the head and neck?}

Definitive surgical excision should be performed with safety margins preferentially within 4-6 weeks of initial diagnosis. In malignant melanoma, total excision of the primary tumor plays an important role in reducing the risk of local recurrence and increasing the disease-free survival. According to the current recommendations based on both prospective, randomised studies and international consensus conferences, safe but narrow margins are appropriate contrary to the formerly used procedures; because no additional improvement on survival has been determined with extended and wide surgical margins $(4 \mathrm{~cm})^{[15-18]}$. Regarding to this context, the extent of surgical margin according to T-stage and tumor thickness is presented in Table 2 [American foint Committee on Cancer (AFCC) 8th edition $]^{[11]}$.

Table 2. Surgical margins according to T-stage and tumor thickness in malignant melanoma.

\begin{tabular}{|ccc|}
\hline T-Stage & Tumor thickness & Surgical margin (Recommendation) \\
\hline Tis & In situ & $0.5-1.0 \mathrm{~cm}$ \\
T1 & $<1.0 \mathrm{~mm}$ & $1.0 \mathrm{~cm}$ \\
T2 & $1.0-2.0 \mathrm{~mm}$ & $1-2 \mathrm{~cm}$ \\
T3 & $2.0-4.0 \mathrm{~mm}$ & $2.0 \mathrm{~cm}$ \\
T4 & $>4.0 \mathrm{~mm}$ & $2.0 \mathrm{~cm}$ \\
\hline
\end{tabular}

Despite the data presented in Table 2, surgical margins should be individualized according to the anatomic neigh- borhoods and relationships. It is known that the presence of vital structures in the head and neck region and the difficulty of identifying tumor boundaries due to sun exposure require careful consideration of surgical margins in skin cancers. In relation to this clinical challenge, we have reported there liable role of "staged surgery" for the reduction of local recurrences in high-risk non-melanoma skin cancers ${ }^{[19]}$. Furthermore, Moyer et al. concluded that staged tumor resection was an effective and useful technique and decreased local recurrences in cutaneous malignant melanoma of the head and neck ${ }^{[20]}$.

\section{The Management of Lymph Nodes in Cutaneous Malignant Melanoma}

An additional procedure is not recommended for in situ or Stage Ia malignant melanoma cases $[<0.8 \mathrm{~mm}$, ulceration $(-)]$. The current approach to the lymph nodes due to clinical evaluation of cases with a tumor thickness $>0.8 \mathrm{~mm}$ is presented in Figure1.

In patients with cutaneous malignant melanoma, lymph node positivity can be detected in two different clinical situations (Figure 1): (i) clinical and radiological evaluation and (ii) SLN biopsy.

\section{What should I do when a lymph node positiv- ity was detected in clinical and/or radiological evaluation?}

According to the current staging system ${ }^{[8]}$, lymph node involvement has been staged as a stage III malignant melano$\mathrm{ma}^{[21]}$. Therefore, therapeutic lymph node dissection with large tumor excision is recommended ${ }^{[3]}$. Risk of regional spread into the intraparotideal lymph nodes particularly in melanomas located on the face and auricle, should be
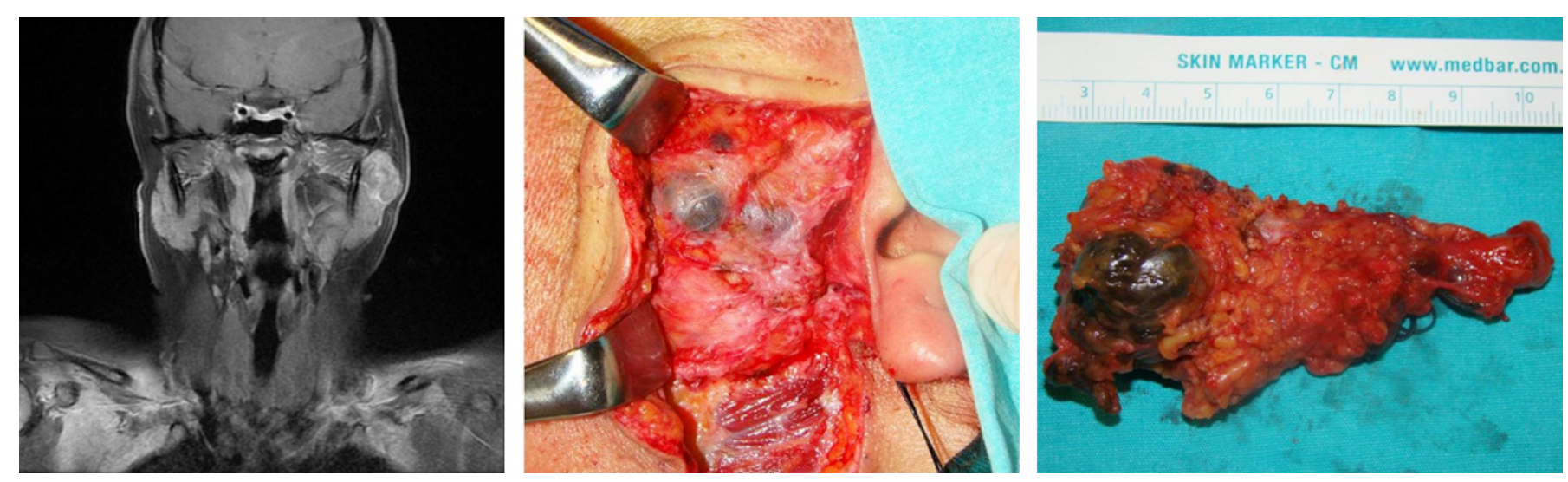

Figure 1. A case with intraparotideal lymph node metastasis of primary conjunctival melanoma. 
kept in mind. In case of positive lymph nodes in the parotid gland, only superficial parotidectomy is inadequate and adding dissection of neck lymph nodes is recommended ${ }^{[2]}$ (Figure 2). Moreover, Mayo Clinic suggested to perform total parotidectomy for patients with metastatic malignant melanoma and advocated that total parotidectomy might provide a better regional control when compared with superficial parotidectomy ${ }^{[23]}$. Adjuvant radiotherapy may be indicated for locoregional treatment in selected cases (high-risk cases, positive number of lymph nodes, macroscopic extranodal involvement, etc.). Agrawal et al. have a large retrospective review on the role of adjuvant RT in controlling nodal recurrence. They demonstrated that at a median 5 years follow-up regional recurrence observed in $10 \%$ of patient selected to receive adjuvant RT, compared to $41 \%$ on who declined adjuvant RT ${ }^{[24]}$. Additionally, other current strategies for these patients are: (i) Observation, (ii) Nivolumab, (iii) Dabrafenib/ trametinib (especially for cases with BRAF V600 mutation), (iv) High dose ipilimumab, (v) Interferon alfa or (vi) Biochemotherapy. Therefore, adjuvant treatments should be individualized and discussed in multidisiplinary head and neck tumor board.

\section{Observation or SLN biopsy? When the clinical lymph node is negative?}

Sentinel lymph node biopsy is essential and strongly recommended for the complete staging of primary melanoma (Figure 3). The procedure is indicated especially for intermediate thickness melanoma (pT2/3). Nevertheless, benefits of SLN biopsy are still under debate. Recently, two

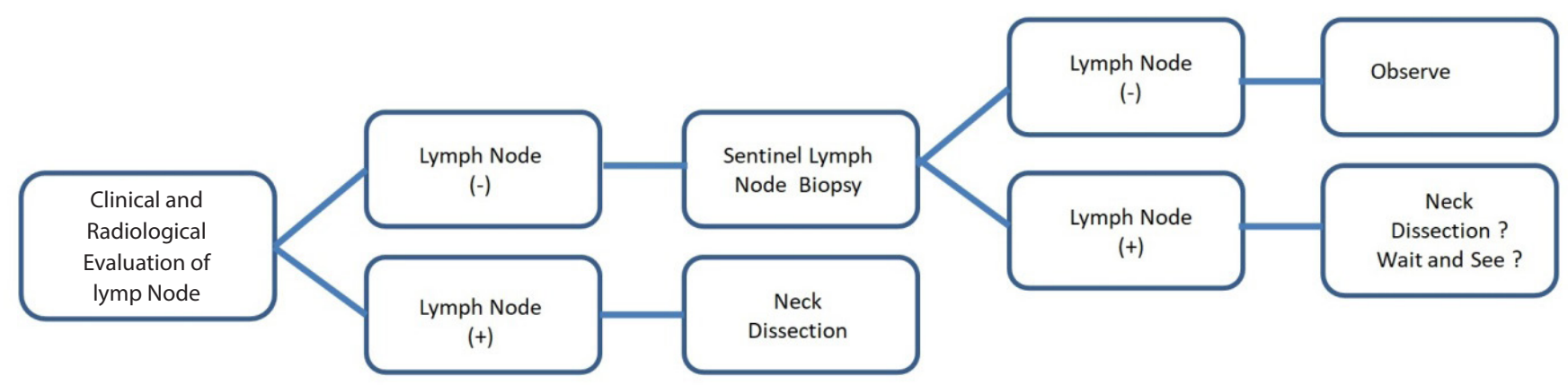

Figure 2. The clinical and radiological evaluation of lymph nodes in cutaneous malignant melanoma.
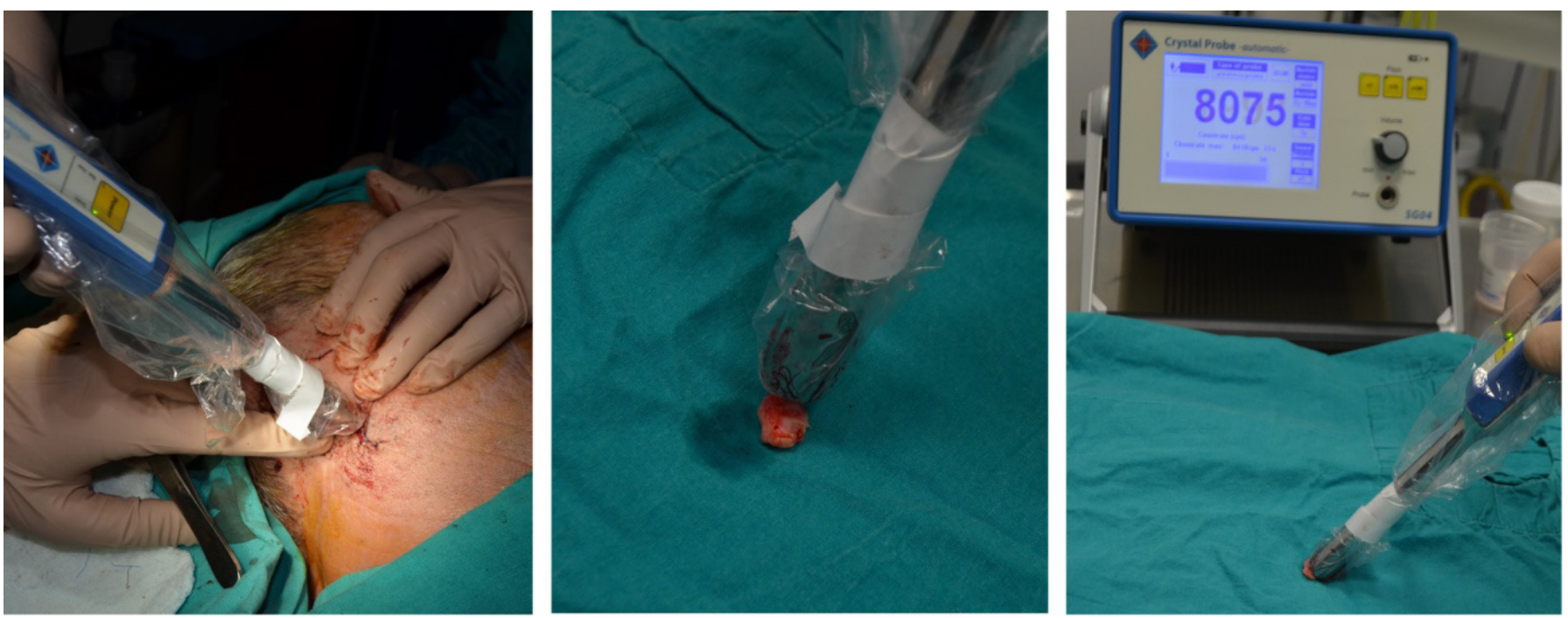

Figure 3. Sentinel lymph node biopsy procedure for melanoma. 
different clinical studies with high level of evidence were focused on to clarify the role of SLN biopsy on survival. In 2006, Multicenter Selective Lymphadenectomy Trial-I (MSLT-I) study was presented by Morton et al. ${ }^{[25]}$. In this study, 1269 patients with malignant melanoma were randomized into two groups as "Observation" vs. "SLN biopsy" (Observation: 500 cases, SLN: 769 cases). There was a statistically significant difference between two groups in terms of 5-year disease-free survival (Observation: 78.3\% + 1.6; SLN biopsy: $73.1+2.1$ ); however, no statistically significant difference was observed for melanoma specific survival (Observation: 87.1\% + 1.3; SLN biopsy: 86.6\% +1.6). In 2014, another clinical study was published in New England Fournal of Medicine about the comparative analysis of "Observation" vs "SLN biopsy" in patients with medium and thick malignant melanoma ${ }^{[26]}$. According to this report, authors were unable to determine statistically significant difference in melanoma-specific survival in both patients with medium-malignant melanoma (Observation: 5 - and 10-year survival: $85.7 \pm 1.6$ and $78.3 \pm 2.0$ vs SLN biopsy: 5 - and 10-year survival: $86.6 \pm 1.3$ and 81.4 \pm 1.5 ) and patients with thick-malignant melanoma (Observation: 5 -, and 10-year survival: $67.5 \pm 4.5$ and $64.4 \pm$ 4.6, respectively vs SLN biopsy: 5- and 10-year survival: $67.0 \pm 3.7$ and $58.9 \pm 4.1$ ). However, statistically significant differences were found in terms of disease-free survival in both patients with medium-malignant melanoma (Observation: 5 - and 10-year survival: $72.7 \pm 2.1$ and $64.7 \pm 2.3$, SLN biopsy: 5 - and 10-year survival: $77.8 \pm 1.6$ and 71.3 $\pm 1.8)$ and patients with thick-malignant melanoma (Observation: 5 - and 10-year survival: $43.7 \pm 4.7$ and $40.5 \pm$ 4.7, SLN biopsy: 5 - and 10-year survival: $56.2 \pm 3.9$ and $50.7 \pm 4.0$, respectively). Therefore, SLN biopsy is recommended for the patients with tumor thickness> $0.8 \mathrm{~mm}$ and no lymph node involvement was detected in clinical evaluation. However, Sladden et al. criticized the reliability of MSLT-1 final report results as being the outcome of post-randomization subgroup analyses ${ }^{[27]}$.

\section{Is SLN biopsy effective in cutaneous malig- nant melanoma of the head and neck?}

Although SLN biopsy is recommended for the management of patients with early stage cutaneous malignant melanoma, head and neck is highly different than the other parts of the body due to complex lymphatic system and high lymph node density. A systematic review evaluated the efficacy of SLN biopsy in patients with cutanoeus malignant melanoma of the head and neck, and reported that false negativity rate was remarkably high $[20.4 \%$ (3.3$44.0 \%)]$ despite of high diagnostic rate [94.0\% (64.8\%)] [28]. In addition, a retrospective analysis of 153 patients with cutaneous malignant melanoma of the head and neck found that the false negativity rate was $32.1 \%$. The authors emphasized that the most important risk factor for the false negativity was the removal of a single lymph node ${ }^{[29]}$. Furthermore, aggressive malignant melanomas may spread to non-sentinel node sites, or skip sentinel nodes; hence a negative SLN biopsy does not exclude locoregional or metastatic disease. "Final trial report of sentinel-node biopsy versus nodal observation in melanoma" demonstrated that half or two-thirds of patients who develop metastases, had negative sentinel nodes. Consequently, the high rate of false negativity in patients who underwent SLN biopsy for malignant melanoma in the head and neck region should not be overlooked when the negative impact of regional recurrence on survival was considered.

\section{What is the best strategy (Observation or Lymph node dissection) when a lymph node in- volvement was reported after SLN biopsy?}

In malignant melanoma, the application of complementary neck dissection and its role on survival after lymph node positivity at SLN biopsy has been discussed for many years. According to current The National Comprehensive Cancer Network or European guidelines, patients with SLNB-positive stage III nodal disease should undergo a complementary neck dissection and recommended as a standart of care. On the other hand despite the guideline recommendation, review of the National Cancer Data Base (2004-2005) revealed only $50 \%$ of patients with a positive SLNB undergoing complementary neck dissection ${ }^{[30]}$. There are many studies investigating the effectiveness and necessity of complementary neck dissection. However DECOD-SLT was the first clinical study with high level of evidence, in which 483 patients with malignant melanoma and SLN biopsy (+) were included. Two hundred forty one patients underwent observation and 242 patients underwent complementary neck dissection. According to this prospective multicenter randomized trial, both strategies provided similiar oncological outcomes ${ }^{[31]}$. Therefore, authors emphasized that complementary lymph node dissection is not mandatory after SLN biopsy especially for patients with micrometastasis. Subsequently, Multicenter Selective Lymphadenectomy Trial-II (MSLT-II) study was 
published in $2017^{[32]}$. The results of this study showed that supplemental lymph node dissection after SLN biopsy is beneficial for regional control, not for melanoma-specific survival. Therefore, authors mentioned that dissection related complications should be considered before the application of complementary neck dissection.

\section{Conclusion}

Briefly, every surgeon should pay special attention on the following topics in patients with cutaneous malignant melanoma of the head and neck: (i) the biopsy technique

\section{References}

1. Boring CC, Squires TS, Tong T, Montgomery S. Cancer statistics, 1994. CA Cancer J Clin 1994;44(1):7-26.

2. Leiter U, Garbe C. Epidemiology of melanoma and nonmelanoma skin cancer--the role of sunlight. Adv Exp Med Biol 2008;624:89-103. doi: 10.1007/978-0-387-77574-6_8

3. Whiteman DC, Green AC, Olsen CM. The Growing Burden of Invasive Melanoma: Projections of Incidence Rates and Numbers of New Cases in Six Susceptible Populations through 2031. J Invest Dermatol 2016;136(6):1161-71. doi: 10.1016/j.jid.2016.01.035

4. Torre LA, Bray F, Siegel RL, Ferlay J, Lortet-Tieulent J, Jemal A. Global cancer statistics, 2012. CA Cancer J Clin 2015;65(2):87-108. doi: $10.3322 /$ caac. 21262

5. Hacıkamiloğlu E, Gültekin M, Boztaş G, et al. Türkiye Kanser İstatistikleri. Ankara: T.C. Sağlık Bakanlığı Türkiye Halk Sağlığı Kurumu; 2017. Available from: https://hsgm.saglik.gov.tr/depo/birimler/kanser-db/istatistik/2014-RAPOR._uzuuun.pdf.

6. Chen ST, Geller AC, Tsao H. Update on the Epidemiology of Melanoma. Curr Dermatol Rep 2013;2(1):24-34. doi: 10.1007/s13671-012-0035-5

7. McGovern VJ, Mihm MC, Jr., Bailly C, et al. The classification of malignant melanoma and its histologic reporting. Cancer 1973;32(6):1446-57.

8. Amin MB, American Joint Committee on Cancer., American Cancer Society. AJCC cancer staging manual. Eight edition / editor-in-chief, Mahul B. Amin, MD, FCAP ; editors, Stephen B. Edge, MD, FACS and 16 others ; Donna M. Gress, RHIT, CTR - Technical editor ; Laura R. Meyer, CAPM - Managing editor. ed. Chicago IL: American Joint Committee on Cancer, Springer; 2017. p. xvii, 1024 pages.

9. Elder DE. Precursors to melanoma and their mimics: nevi of special sites. Mod Pathol 2006;19 Suppl 2:S4-20. doi: 10.1038/modpathol.3800515

10. Salerni G, Carrera C, Lovatto L, et al. Characterization of 1152 lesions excised over 10 years using total-body photography and digital dermatoscopy in the surveillance of patients at high risk for melanoma. J Am Acad Dermatol 2012;67(5):836-45. doi: 10.1016/j.jaad.2012.01.028

11. Network NCC. Melanoma (Version 2.2018) 2018 [08.06.2018]. Available from: https://www.nccn.org/professionals/physician_gls/pdf/melanoma.pdf. should include the tumor in full layer. (ii) the surgical margin should be determined according to the tumor thickness. (iii) a"staged excision" of primary tumor might be performed at the head and neck region. (iv) SLN biopsy should be considered/ recommended in patients with a tumor thickness $>0.8 \mathrm{~mm}$. (v) SLN biopsy should be applied carefully in head and neck region. (vi) In case of SLN biopsy positivity, the advantages and disadvantages of lymph node dissection should be considered and discussed with the patient.

12. Cangiarella J, Symmans WF, Shapiro RL, et al. Aspiration biopsy and the clinical management of patients with malignant melanoma and palpable regional lymph nodes. Cancer 2000;90(3):162-6.

13. Cha J, Kim S, Wang J, Yun M, Cho A. Evaluation of (18)F-FDG PET/ CT Parameters for Detection of Lymph Node Metastasis in Cutaneous Melanoma. Nucl Med Mol Imaging 2018;52(1):39-45. doi: 10.1007/ s13139-017-0495-4

14. Gold JS, Jaques DP, Busam KJ, Brady MS, Coit DG. Yield and predictors of radiologic studies for identifying distant metastases in melanoma patients with a positive sentinel lymph node biopsy. Ann Surg Oncol 2007;14(7):2133-40. doi: 10.1245/s10434-007-9399-3

15. Balch CM, Urist MM, Karakousis CP, et al. Efficacy of 2-cm surgical margins for intermediate-thickness melanomas (1 to $4 \mathrm{~mm}$ ). Results of a multi-institutional randomized surgical trial. Ann Surg 1993;218(3):2627; discussion 7-9.

16. Cohn-Cedermark G, Rutqvist LE, Andersson R, et al. Long term results of a randomized study by the Swedish Melanoma Study Group on 2-cm versus 5 -cm resection margins for patients with cutaneous melanoma with a tumor thickness of 0.8-2.0 mm. Cancer 2000;89(7):1495-501.

17. Haigh PI, DiFronzo LA, McCready DR. Optimal excision margins for primary cutaneous melanoma: a systematic review and meta-analysis. Can J Surg 2003;46(6):419-26.

18. Veronesi U, Cascinelli N, Adamus J, et al. Thin stage I primary cutaneous malignant melanoma. Comparison of excision with margins of 1 or $3 \mathrm{~cm}$. N Engl J Med 1988;318(18):1159-62. doi: 10.1056/ NEJM198805053181804

19. Eskiizmir G, Gencoglan G, Temiz P, Hircin Z, Ermertcan A. Staged-surgery with permanent pathology for the management of high-risk nonmelanoma skin cancer of the nose. Eur Arch Otorhinolaryngol 2011;268(1):117-21. doi: 10.1007/s00405-010-1324-x

20. Moyer JS, Rudy S, Boonstra PS, et al. Efficacy of Staged Excision With Permanent Section Margin Control for Cutaneous Head and Neck Melanoma. JAMA Dermatol 2017;153(3):282-8. doi: 10.1001/jamadermatol.2016.4603

21. Gershenwald JE, Scolyer RA, Hess KR, et al. Melanoma staging: Evi- 
dence-based changes in the American Joint Committee on Cancer eighth edition cancer staging manual. CA Cancer J Clin 2017;67(6):472-92. doi: $10.3322 /$ caac. 21409

22. Pathak I, O’Brien CJ, Petersen-Schaeffer K, et al. Do nodal metastases from cutaneous melanoma of the head and neck follow a clinically predictable pattern? Head Neck 2001;23(9):785-90.

23. Thom JJ, Moore EJ, Price DL, Kasperbauer JL, Starkman SJ, Olsen KD. The Role of Total Parotidectomy for Metastatic Cutaneous Squamous Cell Carcinoma and Malignant Melanoma. JAMA Otolaryngol Head Neck Surg 2014;140(6):548-54. doi: 10.1001/jamaoto.2014.352

24. Agrawal S, Kane JM, 3rd, Guadagnolo BA, Kraybill WG, Ballo MT. The benefits of adjuvant radiation therapy after therapeutic lymphadenectomy for clinically advanced, high-risk, lymph node-metastatic melanoma. Cancer 2009;115(24):5836-44. doi: 10.1002/cncr.24627

25. Morton DL, Thompson JF, Cochran AJ, et al. Sentinel-node biopsy or nodal observation in melanoma. N Engl J Med 2006;355(13):1307-17. doi: 10.1056/NEJMoa060992

26. Morton DL, Thompson JF, Cochran AJ, et al. Final trial report of sentinel-node biopsy versus nodal observation in melanoma. N Engl J Med 2014;370(7):599-609. doi: 10.1056/NEJMoa1310460

27. Sladden M, Zagarella S, Popescu C, Bigby M. No survival benefit for patients with melanoma undergoing sentinel lymph node biopsy: critical appraisal of the Multicenter Selective Lymphadenectomy Trial-I final report. Br J Dermatol 2015;172(3):566-71. doi: 10.1111/bjd.13675

28. de Rosa N, Lyman GH, Silbermins D, et al. Sentinel node biopsy for head and neck melanoma: a systematic review. Otolaryngol Head Neck Surg 2011;145(3):375-82. doi: 10.1177/0194599811408554

29. Miller MW, Vetto JT, Monroe MM, Weerasinghe R, Andersen PE, Gross ND. False-negative sentinel lymph node biopsy in head and neck melanoma. Otolaryngol Head Neck Surg 2011;145(4):606-11. doi: 10.1177/0194599811411878

30. Bilimoria KY, Balch CM, Bentrem DJ, et al. Complete lymph node dissection for sentinel node-positive melanoma: assessment of practice patterns in the United States. Ann Surg Oncol 2008;15(6):1566-76. doi: 10.1245/s10434-008-9885-2

31. Leiter U, Stadler R, Mauch C, et al. Complete lymph node dissection versus no dissection in patients with sentinel lymph node biopsy positive melanoma (DeCOG-SLT): a multicentre, randomised, phase 3 trial. Lancet Oncol 2016;17(6):757-67. doi: 10.1016/S1470-2045(16)00141-8

32. Faries MB, Thompson JF, Cochran AJ, et al. Completion Dissection or Observation for Sentinel-Node Metastasis in Melanoma. N Engl J Med 2017;376(23):2211-22. doi: 10.1056/NEJMoa1613210

This is an open access article distributed under the terms of the Creative Commons Attribution-NonCommercial-NoDerivs 3.0 Unported (CC BY- NC-ND3.0) Licence (http://creativecommons.org/licenses/by-nc-nd/3.0/) which permits unrestricted noncommercial use, distribution, and reproduc- tion in any medium, provided the original work is properly cited.

Please cite this article as: Özgür E., Karakullukçu B., Eskiizmi G., Current Treatment Strategies in Cutaneous Malignant Melanoma of the Head and Neck. ENT Updates 2019;9(1): 25-33 